\title{
Meta-analysis of pharmacist-led and pharmacist-physician intervention on blood pressure control
}

\author{
Merve Memisoglu, ${ }^{1}$ Yusuf Çelik ${ }^{2}$ \\ ${ }^{1}$ Department of Social Pharmacy, Faculty of Pharmacy; and ${ }^{2}$ Department of Medical Informatics and Biostatistics, Faculty of \\ Medicine, Biruni University, Istanbul, Turkey
}

\begin{abstract}
Effective intervention is a significant component in the improvement of blood pressure control and patient adherence. Blood pressure control includes different self-monitoring techniques, mobile health monitoring, or healthcare professionals' interventions. This study aims to compare, analyze, and interpret the effectiveness of pharmacist-physician collaboration and pharmacist-led interventions. Meta-analysis was performed using MEDLINE via PubMed, EMBASE, EBSCO, Web of Science, Scopus, and the Cochrane Library databases between 2008-2018. Of the 51 relevant systematic reviews identified, 15 were of sufficient quality and included in the data synthesis. The breakdown of the 15 included $7(n=2026)$ pharmacist and 8 pharmacist-physician interventions $(\mathrm{n}=2361)$. The impact of pharmacist-physician collaboration and pharmacist-led interventions on Systolic Blood Pressure was $-8.22(-11.01 ;-5.42)(\mathrm{P}<0.01)$ and -7.68 $(-9.30 ;-6.06)(\mathrm{P}=0.35)$, respectively. On the other hand, similar correlation for Diastolic Blood Pressure for the impact of pharmacist-physician collaboration and pharmacist-led interventions was $-3.55(-4.54 ;-2.55)(\mathrm{P}=0.49)$ and $-2.58(-3.76 ;-1.39)(\mathrm{P}=0.24)$, respectively. These results suggest that both interventions are effective for blood pressure control. However, when two meta-analyses were compared, it was found that pharmacist-physician collaboration was more effective than pharmacist-led interventions. This finding highlights the importance of multidisciplinary approaches during blood pressure control procedures. When a holistic view is considered; especially cost-effectiveness, future studies must be diversified to encompass a broader context and impact analysis.
\end{abstract}

\section{Introduction}

According to the World Health Organization (WHO), hypertension is described as a 'silent killer'

Correspondence: Merve Memisoglu, Biruni University, 10. Y11 Caddesi, Protokol Yolu No: 4534010 Topkapi, Istanbul, Turkey. Tel.: +90.212.4448276 - Fax: +90.212.4164646.

E-mail: mmerve.memisoglu@gmail.com

Key words: Meta-analysis; hypertension; blood pressure control; pharmacist-led intervention; physician-pharmacist intervention; physician-pharmacist collaborative management.

Contributions: the authors contributed equally. Each contribution was detailed in the Materials and Methods section.

Conflict of interests: the authors declare no potential conflict of interests.

Ethical statement: no approval was needed from the University's Institutional Review Board since this study was a metaanalysis.

Received for publication: 12 January 2021.

Accepted for publication: 9 February 2021

This work is licensed under a Creative Commons Attribution NonCommercial 4.0 License (CC BY-NC 4.0).

${ }^{\circ}$ Copyright: the Author(s), 2021

Licensee PAGEPress, Italy

Italian Journal of Medicine 2021; 15:145-153

doi:10.4081/itjm.2021.1463 that can cause heart disease, stroke and kidney failure, premature death and disability. ${ }^{1}$ and the aging population increases hypertension. ${ }^{2}$ Forecasters estimate that by 2025 , over 1.5 billion people are expected to suffer from hypertension, which is a severe public health concern. ${ }^{3}$ However, the WHO also reports that it will be both preventable and treatable if all stakeholders such as governments, health workers, civil society, and individuals cooperate to reduce hypertension. ${ }^{1}$ This notification supports the necessity of pharmacist and pharmacist-physician interventions, which are the main topic of our study.

For well-controlled blood pressure, systolic blood pressure and diastolic blood pressure should be less than 140/90 mm Hg. Otherwise, high blood pressure increases the risk of ischemic heart disease 3- to 4-fold, of overall cardiovascular disease by 2 - to 3 -fold, ${ }^{4}$ and the incidence of stroke increases 3 - to 8 -fold in patients with borderline and definite hypertension, respectively. ${ }^{5}$

Many factors such as race/ethnicity, socio-economical, and health literacy affect the quality of communication with the patient with hypertension. ${ }^{6}$ Therefore, blood pressure management requires the participation of all stakeholders, such as patients, families, and in particular, health care professionals. This management includes enhancing awareness, lifestyle modifications, access to treatment, evidence-based medicine, increasing medical adherence, and monitoring. ${ }^{7}$

Several studies have shown that physician-pharma- 
cist collaborative management (PPCM) has a remarkable impact on blood pressure control and other chronic diseases. ${ }^{8-10}$ Others have also shown the importance of Home Blood Pressure Tele-monitoring as another technique. The same studies have underlined the effectiveness of Web-Based Home Blood Pressure Monitoring with Pharmacist Support. ${ }^{11-15}$ In addition to meta-analysis related to the impact of the pharmacist on patient care, ${ }^{16}$ certain studies have emphasized the necessity of pharmacist-led interventions as pharmacists are the most accessible healthcare professionals - and highly capable of the management of hypertension. ${ }^{17-21}$

Meanwhile, other studies have reported that teambased health care delivery models such as physicianpharmacist collaboration are important in meeting patient needs, improving health care quality ${ }^{22}$ and, in particular, in effective blood pressure management. However, they have also stressed the comparatively higher cost of care. ${ }^{23}$

For this reason, our study aims to evaluate the intervention of the pharmacist and pharmacist-physician cooperation by meta-analyses and interprets the effectiveness of these interventions in view of all available literature.

\section{Materials and Methods}

We have followed preferred reporting items for systematic reviews and meta-analyses (PRISMA) guidelines for reporting meta-analysis. ${ }^{24,25}$

\section{Data sources and search strategy}

Primary data sources used are; MEDLINE via PubMed, EMBASE, EBSCO, Web of Science, Scopus, and the Cochrane Library, systematically searched by two independent authors (M.M. and Y.C.). These databases were searched for the period from 2008 to May 2018. Search terms included: 'Pharmacist intervention' OR 'Pharmacist care intervention' OR 'Pharmacist' OR 'Pharmacist-physician collaboration management' OR 'Pharmacist-physician intervention' OR 'Pharmacistphysician' OR 'Blood pressure control' AND 'Blood pressure' OR 'High blood pressure' OR 'Hypertension.' We also scanned the references of included studies that met the eligibility criteria.

\section{Study selection}

The inclusion criteria are listed below:

- Randomized controlled trial (RCT);

- Articles published between 2008-2018;

- Articles in the English language;

- Articles with full texts;

- At least 3-month duration of the study;

- A control group;

- Focused on patients with hypertension, but where patients with specific conditions (Diabetes, asthma, etc.) were excluded;

- Described and evaluated the type of intervention and outcomes;

- A pharmacist or a pharmacist in collaboration with a physician for the intervention.

The study screening was made in tandem by two authors (M.M. and Y.C.) independently. One of the researchers was blind to the authors of the articles. Conflicts in evaluating articles for inclusion were resolved by consensus.

Studies were screened for inclusion by reviewing the title and abstract. The screening was limited by publication date and the English language. Metaanalysis was also screened as potentially relevant studies. The last screening, which reviewed full-text articles was performed by two authors (M.M. and Y.C.). The remaining articles were divided into two groups as pharmacist-physician intervention and pharmacist intervention.

\section{Data extraction and quality assessment}

The extraction process was performed by one of our authors and checked for accuracy by another. Data were collected from full texts that extracted the following descriptive information: First author, publication year, country, study design, study duration, sample size, and characteristics of intervention. Our study has no restrictions on age, gender, and ethnicity.

The quality of the selected papers was independently scored, and all data were coded by two researchers (M.M. and Y.C.). Any disagreements between the two authors were resolved by consensus. Otherwise, any disagreement was to be resolved by a third reviewer (T.D.). However, there was no disagreement in our study to require such support.

\section{Data synthesis and analysis}

We used the Cochrane Collaboration tool from the Cochrane Handbook ${ }^{26}$ to assess the risk of bias and the PRISMA statement. The RCTs were graded based on sequence generation, allocation concealment, incomplete outcome data, selective reporting, blinding of participants and personnel, and blinding of the outcome assessment. We categorized these judgments as 'low risk, 'high risk' or 'unclear risk' of bias. All meta-analyses were conducted using 'RStudio Version 1.2.1335, 2019 RStudio, Inc.' for Windows version 10.0 (Copenhagen: The Nordic Cochrane Centre, The Cochrane Collaboration, 2014), at the 5\% significance level.

\section{Results}

A total of 19,412 articles were identified during the initial search (Figure 1). From that group, 109 articles 
were written in different languages. Thus, the initial search revealed 877 potentially relevant studies, and those were selected for our database search. After reviewing the abstract and removing duplicate publications, 51 full-text articles were reviewed for a more detailed evaluation. From that group, 15 studies met the inclusion criteria (pharmacist intervention 7 , PPCM intervention 8). 36 were excluded for the following reasons:

- not an interventional study;

- studied participants with a different disease not relevant to review;

- did not include pharmacists in the study interventions;

- presented pharmaceutical interventions and out- comes investigating neither adherence nor blood pressure;

- presented pharmaceutical interventions and outcomes investigating blood pressure but not adherence;

- investigated medication adherence outcome in the intervention group only, and baseline adherence was not measured.

Each study intervention was categorized as pharmacist-directed care or pharmacist collaborative care.

Studies into PPCM intervention included 2361 participants (1305 interventions and 1056 control studies), and studies on pharmacist intervention included 2026 participants (990 interventions and 1036 control studies).
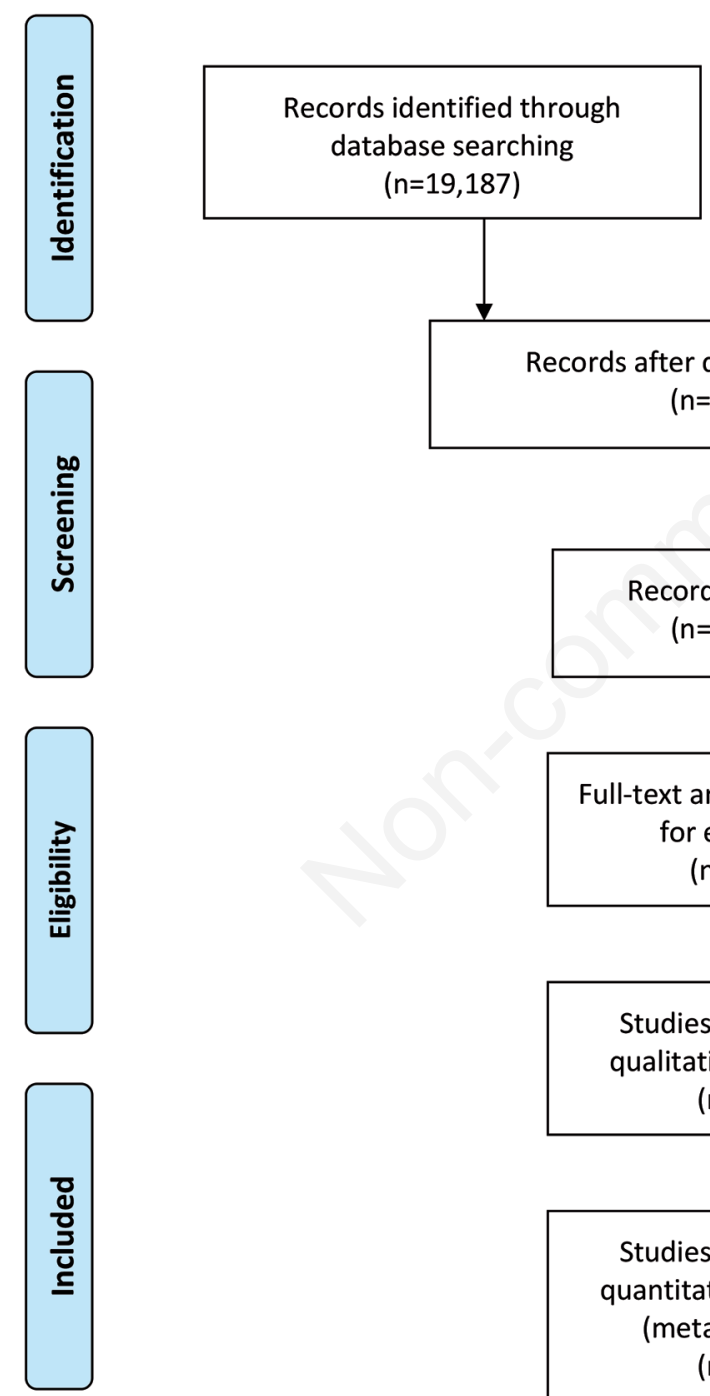

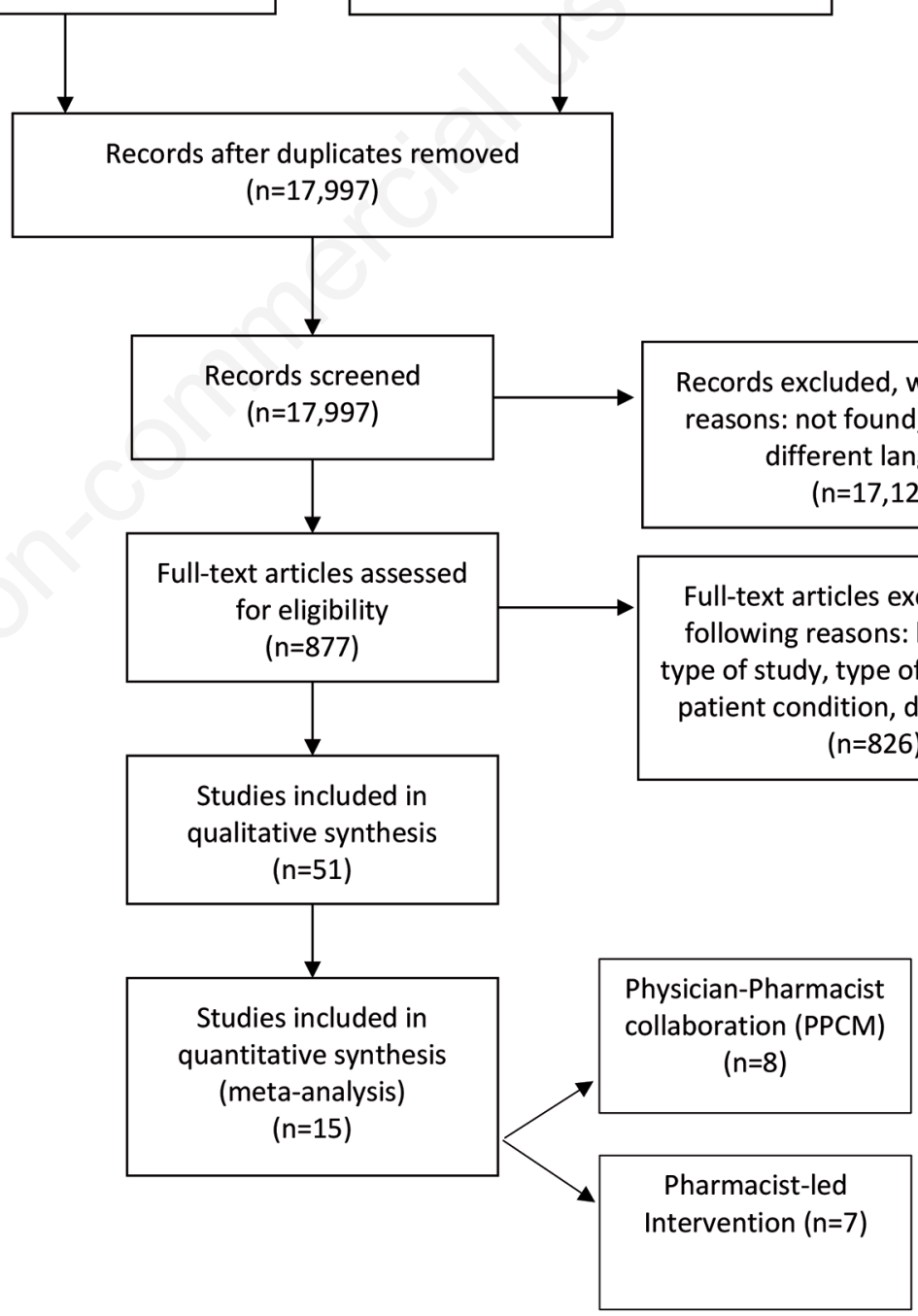

Figure 1. Flow chart of data extracting according to PRISMA. ${ }^{24,25}$ 
The publication years ranged from Jan 2008 to May 2018. Regarding patient characteristics, the mean age of all studies was 48.8 to 68 . Regarding physicianpharmacist collaboration (PPCM), most studies were conducted in the US ( $\mathrm{n}=7)$, and 1 in Jordan. Regarding pharmacist-led interventions, 2 of the studies were conducted in the US, 1 in Australia, 1 in China, 1 in Japan, 1 in Portugal, and 1 in Canada. Study duration ranged from 3 months to 30 months, with most lasting no longer than 12 months. The sample size in each trial ranged from 104 to 723 participants.

Overall, 15 randomized control trials with combined interventions were analyzed where Tables 1 and 2 show the summary of the included study characteristics. ${ }^{10,27-39}$ The mean intervention duration was 11 months for PPCM and 12 months for pharmacist-led intervention. Six of the studies were relatively shortterm ( $<9$ months), and 9 of the studies were long-term (9-30 months). It was found that time of duration was not directly related to blood pressure control (Figures 2-5). However, we can state that the extension of the duration may increase the effectiveness of blood pressure control in pharmacist-led interventions.

According to the random effects model, the corre- lation between article quality scores and the impact of PPCM and pharmacist-led interventions on SBP were $-8.22(-11.01 ;-5.42)(\mathrm{P}<0.01)$ and $-7.68(-9.30$; 6.06) $(\mathrm{P}=0.35)$, respectively (Figures 2 and 3$)$. On the other hand, similar correlation for DBP for the impact of PPCM and pharmacist-led interventions was -3.55 $(-4.54 ;-2.55)(\mathrm{P}=0.49)$ and $-2.58(-3.76 ;-1.39)$ $(\mathrm{P}=0.24)$, respectively (Figures 4 and 5$)$. The mean reduction from baseline to endpoint in PPCM intervention was more than in pharmacist-led interventions.

\section{Discussion}

Hypertension is one of the leading causes of mortality. Therefore, to control high blood pressure, the quality of intervention plays a critical role. For this reason, it is essential to investigate what kind of intervention is more effective in combating this disease.

The findings of Morgado, who performed a metaanalysis between 1999 and 2009, showed that pharmacist interventions improved medication adherence significantly. ${ }^{40}$ Morgado's study was similar to our research except for the different period used (time interval

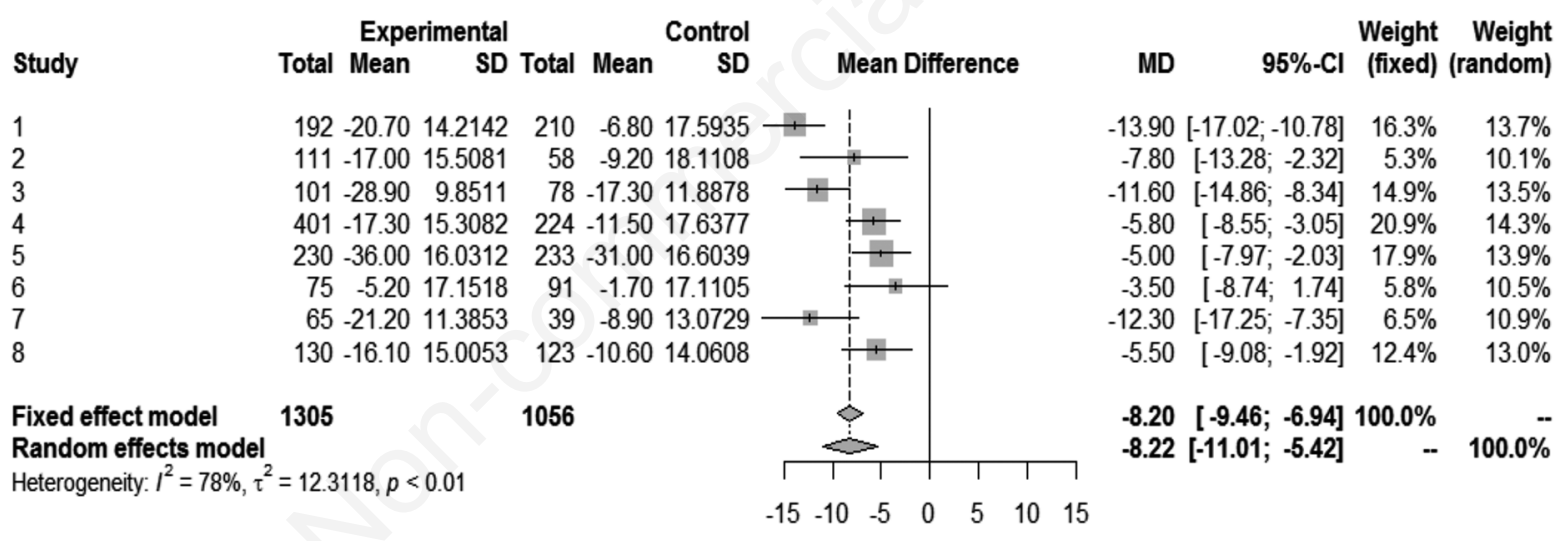

Figure 2. Improvement of systolic blood pressure of physician-pharmacist collaboration intervention.

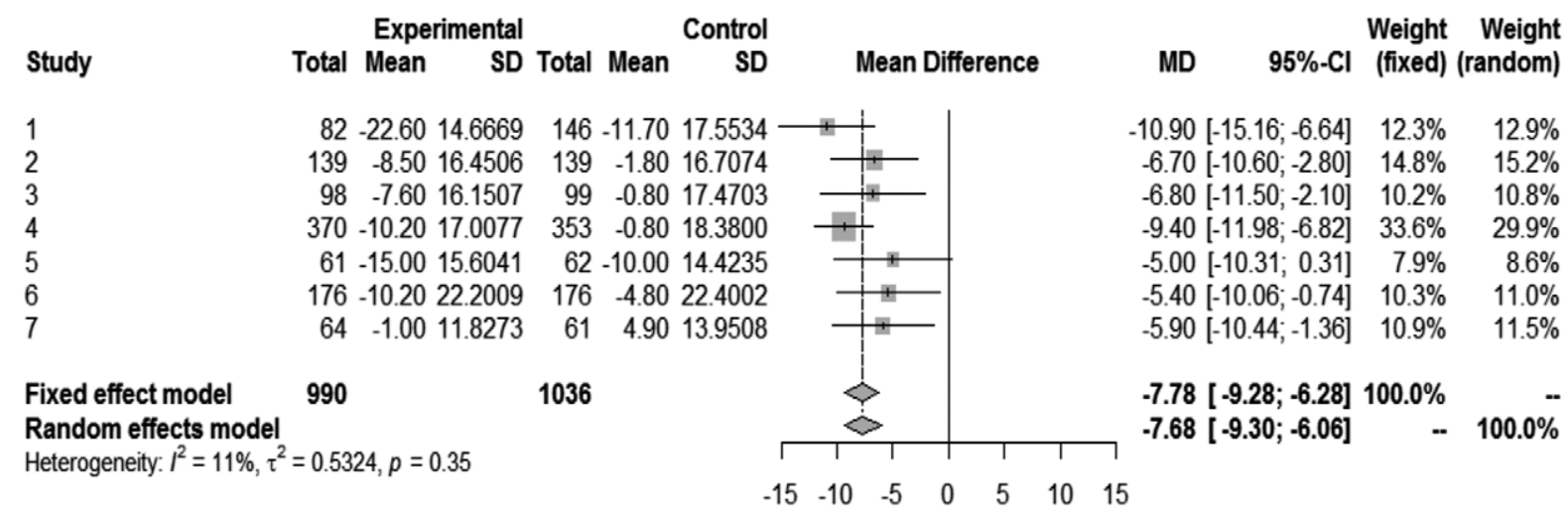

Figure 3. Improvement of systolic blood pressure of pharmacist intervention. 


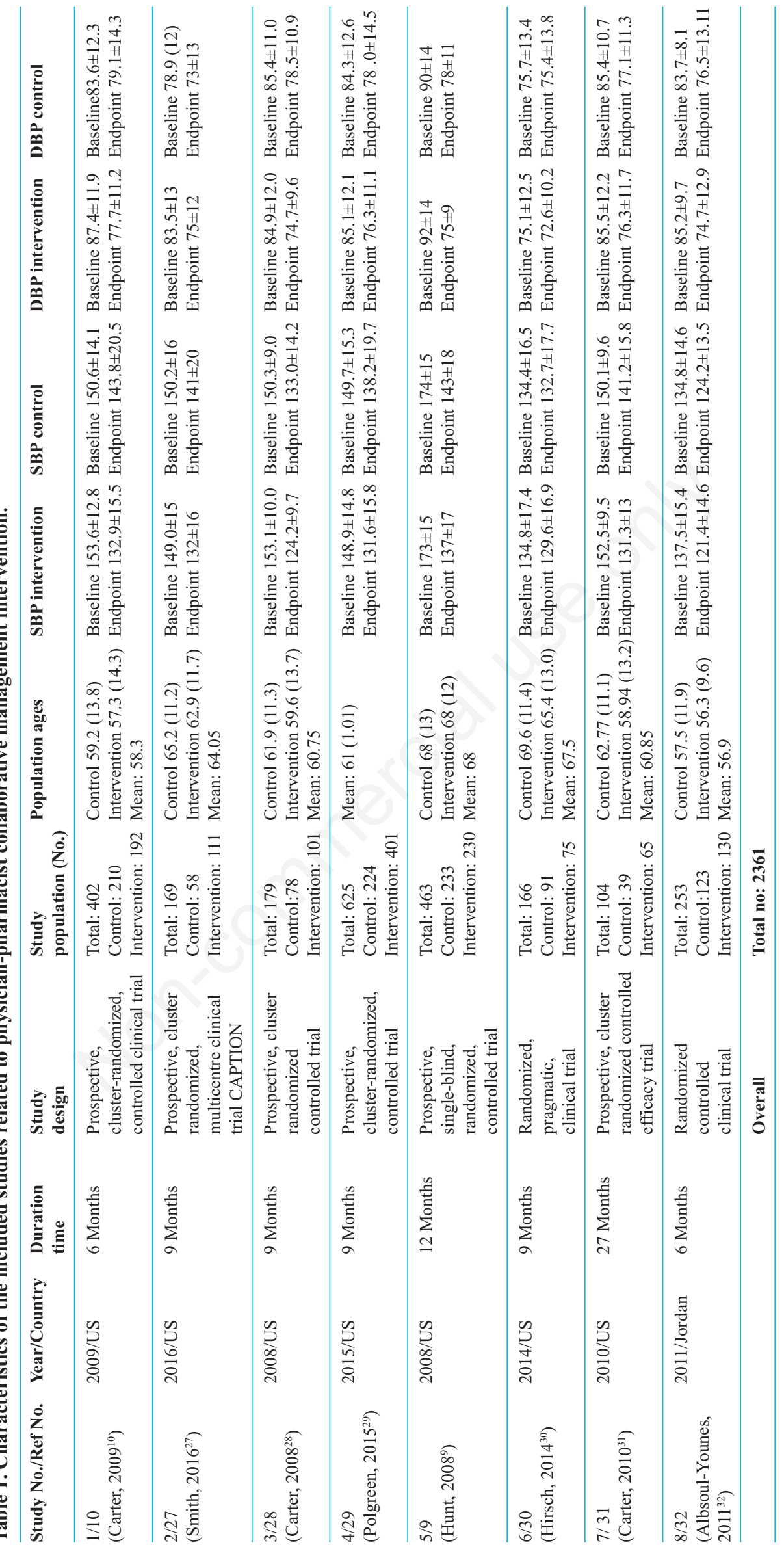


of our study: 2008-2018). In addition, though Morgado's findings only mention pharmacist interventions, the same study covers both methods. Therefore, Morgado's study ${ }^{40}$ was not included in part of our study.

Another previous meta-analysis conducted by Santschi et al. shows that intervention by the pharmacist or pharmacist in collaboration with physicians or nurses improves the risk factor in cardiovascular disease management. ${ }^{41}$ Both studies highlight similar results within our study.

According to our meta-analysis, the pharmacistphysician collaborative intervention increased blood pressure control more than pharmacist-led interventions. However, it should also be noted that teambased care can also increase the cost of care. Additionally, 'Collaboration among Pharmacists and Physicians to Improve Blood Pressure Now' (CAPTION) was known as an effective study to implement PPCM for hypertensive patients in the United States. However, recent data show that no improvement is visible in the blood pressure control rate in the US. ${ }^{42}$

Despite these conflicting data, we can still say that the pharmacist plays a critical role in managing blood pressure..$^{40,41,43-47}$ However, regarding pharmacist-led intervention, an extension of duration can be essential to improve blood pressure control. Therefore, as evidenced by our study, the most reasonable approach would be to adopt pharmacist-physician collaboration and interventions to achieve effective patient care.

On the other hand, this study covers several limitations related to heterogeneity, such as interventions, duration of follow-up, and study population. Many studies could not be included in the meta-analysis because they did not meet specific inclusion criteria such as language or publication date. As more studies were conducted in the USA, the heterogeneity of the population, such as ethnicity, was affected. In the near future, studies should be diversified by incorporating different backgrounds such as regional, urban, $v s$ rural, and the inclusion of other advanced techniques.

\section{Limitation}

This meta-analysis was performed using several databases between 2008-2018. One of the limitations of our research is that the data of the last years (20192020 ) were not reviewed. Another limitation was that

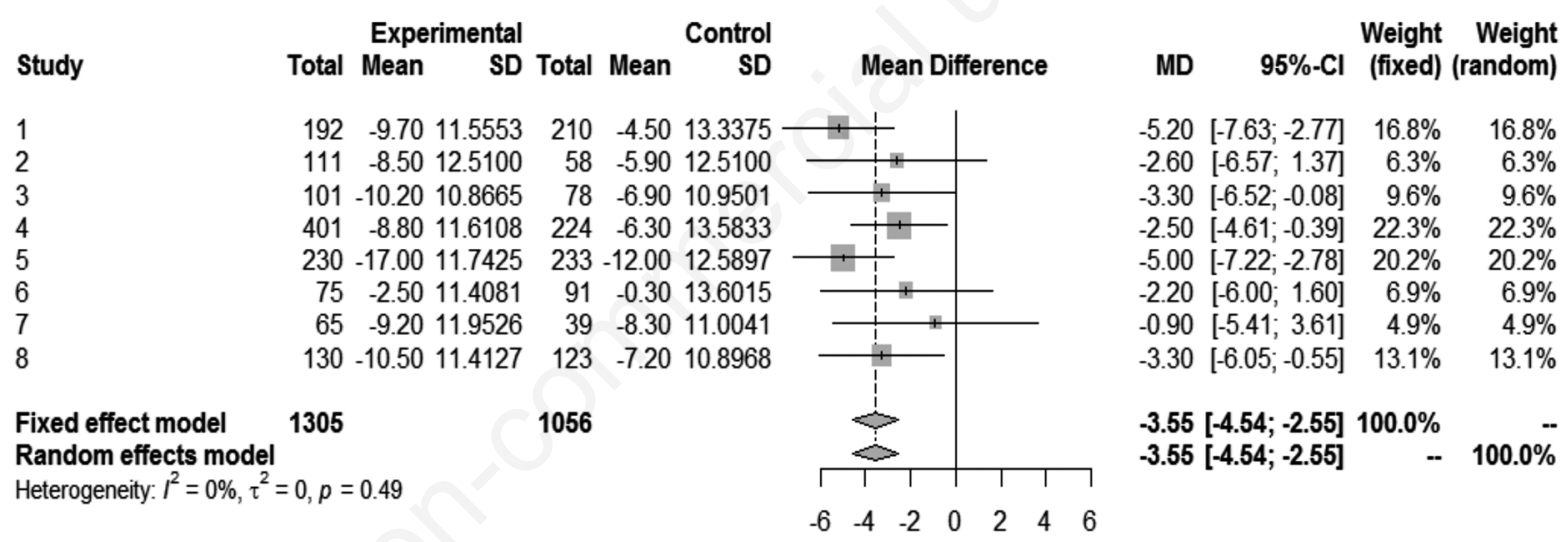

Figure 4. Improvement of diastolic blood pressure for physician-pharmacist collaboration intervention.

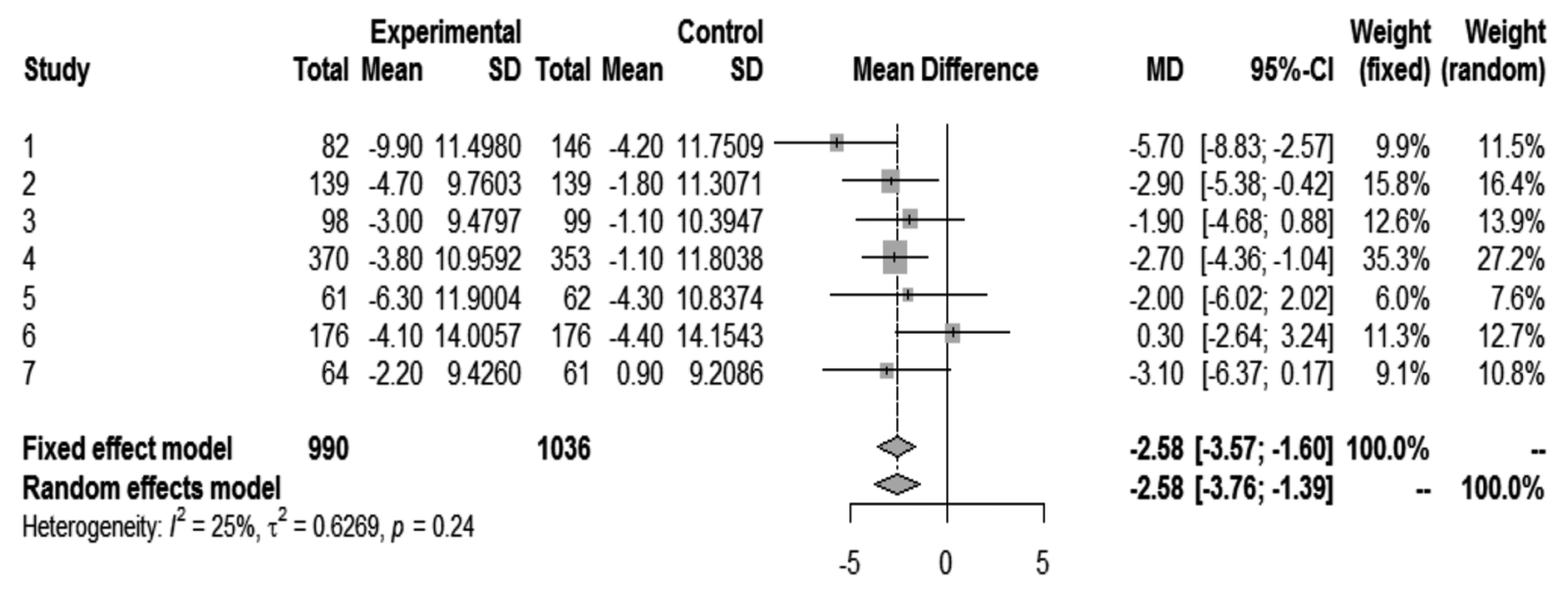

Figure 5. Improvement of diastolic blood pressure for pharmacist intervention. 


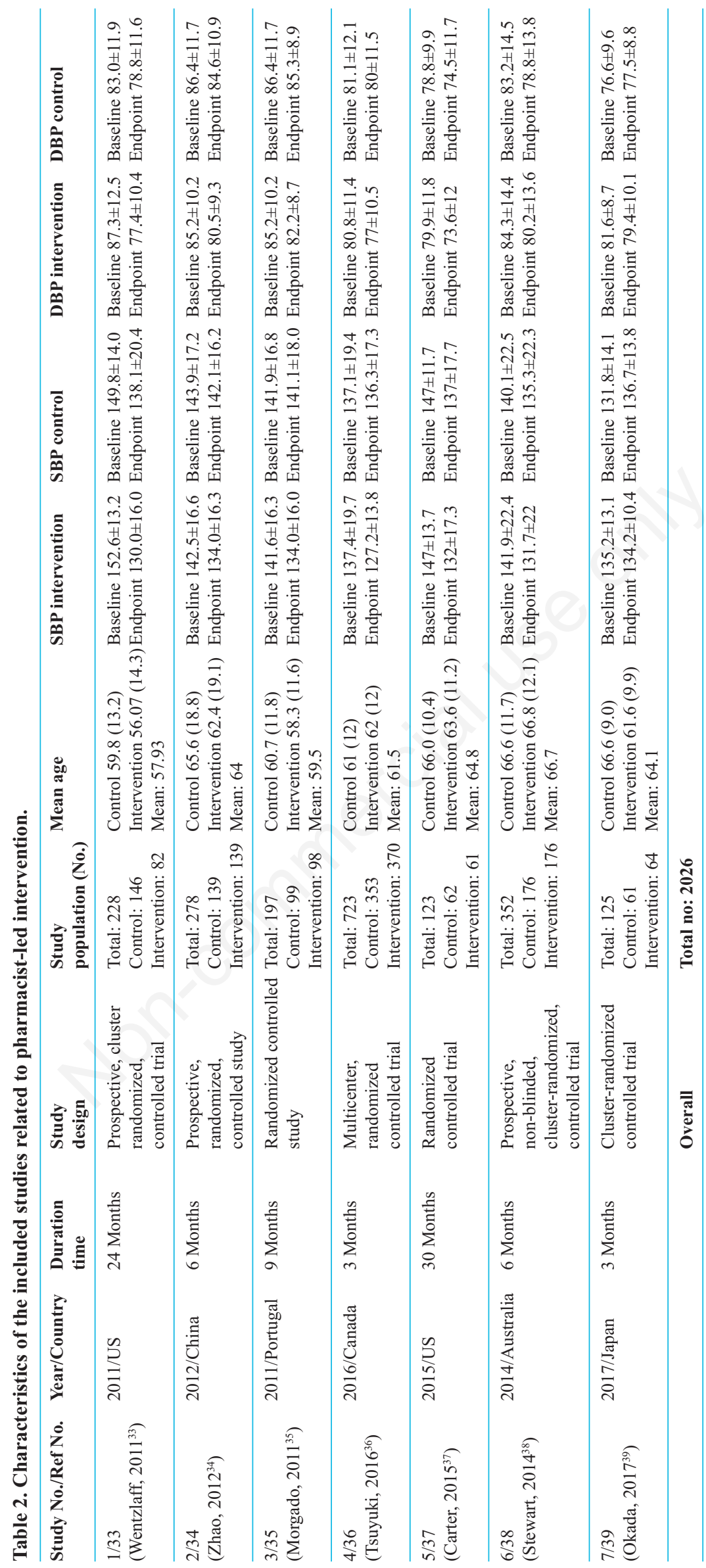


36 studies were excluded from the data synthesis due to not meeting the inclusion criteria. As a result, future studies need to be diversified to encompass a larger sample size and impact analysis.

\section{Conclusions}

Our meta-analysis has revealed that pharmacistphysician collaboration was relatively more effective than pharmacist-led interventions.

This finding highlights the importance of multidisciplinary approaches during blood pressure control procedures. However, when a holistic view is considered, especially including the cost-effectiveness, future studies must be diversified to encompass a broader context and impact analysis. To improve blood pressure control, it is crucial to examine how pharmacists could be more effective within a shorter timeframe, and their precise role in the team.

\section{References}

1. World Health Organization Report. A Global brief of hypertension, World Health Day 2013, WHO/DCO/WHD/ 2013.2 2013. Available from: https://ish-world.com/ ownloads/pdf/global_brief_hypertension.pdf. Accessed: 2013.

2. Robitaille C, Dai S, Waters C, et al. Diagnosed hypertension in Canada: incidence, prevalence and associated mortality. CMAJ 2012;184:49-56.

3. Kearney PM, Whelton M, Reynolds K, et al. Global burden of hypertension: analysis of worldwide data. Lancet 2005;365:217-23.

4. Berenson GS. Association between multiple cardiovascular risk factors and atherosclerosis in children and young adults. The Bogalusa Heart Study. N Engl J Med 1998;338:1650-6.

5. Thompson DW, Furlan AJ. Clinical epidemiology of stroke. Neurol Clin 1996;14:309-15.

6. Ong KL, Cheung BM, Man YB, et al. Prevalence, awareness, treatment, and control of hypertension among United States adults 1999-2004. Hypertension 2007;49:69-75.

7. Go AS, Bauman MA, King SMC, et al. An effective approach to high blood pressure control: a science advisory from the American Heart Association, the American College of Cardiology, and the Centers for Disease Control and Prevention. J Am Coll Cardiol 2014;63:1230-8.

8. Borenstein JE, Graber G, Saltiel E, et al. Physician-pharmacist co-management of hypertension: a randomized, comparative trial. Pharmacotherapy 2003;23:209-16.

9. Hunt JS, Siemienczuk J, Pape G, et al. A randomized controlled trial of team-based care: impact of physicianpharmacist collaboration on uncontrolled hypertension. J Gen Intern Med 2008;23:1966-72.

10. Carter BL, Ardery G, Dawson JD, et al. Physician and pharmacist collaboration to improve blood pressure control. Arch Intern Med 2009;169:1996-2002.

11. Carter BL, Rogers M, Daly J, et al. The potency of team- based care interventions for hypertension: a meta-analysis. Arch Intern Med 2009;169:1748-55.

12. Magid DJ, Olson KL, Billups SJ, et al. A pharmacistled, American Heart Association Heart360 Web-enabled home blood pressure monitoring program. Circ Cardiovasc Qual Outcomes 2013;6:157-63.

13. Mancia G, Facchetti R, Bombelli M, et al. Long-term risk of mortality associated with selective and combined elevation in office, home, and ambulatory blood pressure. Hypertension 2006;47:846-53.

14. Margolis KL, Asche SE, Bergdall AR, et al. Effect of home blood pressure telemonitoring and pharmacist management on blood pressure control: a cluster randomized clinical trial. JAMA 2013;310:46-56.

15. Green BB, Cook AJ, Ralston JD, et al. Effectiveness of home blood pressure monitoring, Web communication, and pharmacist care on hypertension control: a randomized controlled trial. JAMA 2008;299:2857-67.

16. Chisholm-Burns MA, Lee JK, Spivey CA, et al. US pharmacists' effect as team members on patient care: systematic review and meta-analyses. Med Care 2010;923-33.

17. Frail CK, Cooper S, Gallagher T, et al. A technologysupported collaboration between a health plan and a community pharmacy to improve blood pressure control. J Am Pharm Assoc 2017;57:630-4.

18. Koshman SL, Charrois TL, Simpson SH, et al. Pharmacist care of patients with heart failure: a systematic review of randomized trials. Arch Intern Med 2008;168:687-94.

19. Namara KPM, Dunbar JA, Philpot B, et al. Potential of pharmacists to help reduce the burden of poorly managed cardiovascular risk. Aust J Rural Health 2012;20:67-73.

20. Fikri-Benbrahim N, Faus MJ, Martínez-Martínez F, Sabater-Hernández D. Impact of a community pharmacists' hypertension-care service on medication adherence. The AFenPA study. Res Social Adm Pharm 2013;9:797-805.

21. Yarnall KS, Østbye T, Krause KM, et al. Peer reviewed: family physicians as team leaders: 'time' to share the care. Prev Chronic Dis 2009;6:59.

22. Santschi V, Chiolero A, Colosimo AL, et al. Improving blood pressure control through pharmacist interventions: a meta-analysis of randomized controlled trials. J Am Heart Assoc 2014;3:e000718.

23. Altowaijri A, Phillips CJ, Fitzsimmons D. A systematic review of the clinical and economic effectiveness of clinical pharmacist intervention in secondary prevention of cardiovascular disease. J Manage Care Pharm 2013; 19:408-16.

24. Moher D, Liberati A, Tetzlaff J, Altman DG. Preferred reporting items for systematic reviews and meta-analyses: the PRISMA statement. Int J Surg 2010;8:336-41.

25. Hutton B, Salanti G, Caldwell DM, et al. The PRISMA extension statement for reporting of systematic reviews incorporating network meta-analyses of health care interventions: checklist and explanations. Ann Intern Med 2015;162:777-84.

26. Higgins JPT, Green S. Cochrane handbook for systematic reviews of interventions. Chichester, West Sussex, UK; Hoboken NJ: Wiley-Blackwell; 2008.

27. Smith SM, Carris NW, Dietrich E, et al. Physician-pharmacist collaboration versus usual care for treatment-resistant hypertension. J Am Soc Hypertens 2016;10: 307-17. 
28. Carter BL, Bergus GR, Dawson JD, et al. A cluster randomized trial to evaluate physician/pharmacist collaboration to improve blood pressure control. J Clin Hypertens 2008;10:260-71.

29. Polgreen LA, Han J, Carter BL, et al. Cost-effectiveness of a physician-pharmacist collaboration intervention to improve blood pressure control. Hypertension 2015;66:1145-51.

30. Hirsch JD, Steers N, Adler DS, et al. A randomized pragmatic trial of primary care based pharmacist-physician collaborative medication therapy management for hypertension. Clin Ther 2014;36:1244.

31. Carter BL, Doucette WR, Franciscus CL, et al. Deterioration of blood pressure control after discontinuation of a physician-pharmacist collaborative intervention. Pharmacotherapy 2010;30:228-35.

32. Albsoul-Younes AM, Hammad EA, Yasein NA, Tahaineh LM. Pharmacist-physician collaboration improves blood pressure control. Saudi Med J 2011;32:288-92.

33. Wentzlaff DM, Carter BL, Ardery G, et al. Sustained blood pressure control following discontinuation of a pharmacist intervention. J Clin Hypertens 2011;13:431-7.

34. Zhao PX, Wang C, Qin L, et al. Effect of clinical pharmacists pharmaceutical care intervention to control hypertensive outpatients in China. Afr J Pharm Pharmacol 2012;6:48-56.

35. Morgado M, Rolo S, Castelo-Branco M. Pharmacist intervention program to enhance hypertension control: a randomised controlled trial. Int $\mathrm{J}$ Clin Pharm 2011;33:132-40.

36. Tsuyuki RT, Al Hamarneh YN, Jones CA, Hemmelgarn BR. The effectiveness of pharmacist interventions on cardiovascular risk: the multicenter randomized controlled RxEACH trial. J Am Coll Cardiol 2016;67:2846-54.

37. Carter BL, Vander Weg MW, Parker CP, et al. Sustained blood pressure control following discontinuation of a pharmacist intervention for Veterans. J Clin Hypertens 2015;17:701-8.

38. Stewart K, George J, Mc Namara KP, et al. A multifac- eted pharmacist intervention to improve antihypertensive adherence: a cluster-randomized, controlled trial (HAPPy trial). J Clin Pharm Ther 2014;39:527-34.

39. Okada H, Onda M, Shoji M, et al. Effects of lifestyle advice provided by pharmacists on blood pressure: The COMmunity Pharmacists ASSist for Blood Pressure (COMPASS-BP) randomized trial. Biosci Trends 2017;11:632-9.

40. Morgado MP, Morgado SR, Mendes LC, et al. Pharmacist interventions to enhance blood pressure control and adherence to antihypertensive therapy: review and metaanalysis. Am J Health Syst Pharm 2011;68:241-53.

41. Santschi V, Chiolero A, Burnand B, et al. Impact of pharmacist care in the management of cardiovascular disease risk factors: a systematic review and meta-analysis of randomized trials. Arch Intern Med 2011;171:1441-53.

42. Bloch MJ. Recent data from National Health and Nutrition Examination Survey (NHANES) demonstrates no improvement in US blood pressure control rates. J Am Soc Hypertens 2018;12:3-4.

43. Von Muenster SJ, Carter BL, Weber CA, et al. Description of pharmacist interventions during physician-pharmacist co-management of hypertension. Pharm World Sci 2008;30:128-35.

44. Blenkinsopp A. Extended adherence support by community pharmacists for patients with hypertension: a randomised controlled trial. Int $\mathrm{J}$ Pharm Pract 2000;8:165-75.

45. Chabot I, Moisan J, Grégoire JP, Milot A. Pharmacist intervention program for control of hypertension. Ann Pharmacother 2003;37:1186-93.

46. Sookaneknun P, Richards RM, Sanguansermsri J, Teerasut C. Pharmacist involvement in primary care improves hypertensive patient clinical outcomes. Ann Pharmacother 2004;38:2023-8.

47. Stewart B, Brody A, Krishnan AC, et al. An unmet need meets an untapped resource: pharmacist-led pathways for hypertension management for emergency department patients. Curr Hypertens Rep 2019;21:61. 